\title{
Overview of the soybean process in the crushing industry ${ }^{\text {is }}$
}

\author{
Anibal Demarco ${ }^{1, a}$ and Véronique Gibon ${ }^{2,{ }^{*}, \mathrm{~b}}$ \\ ${ }^{1}$ Desmet Ballestra, Buenos Aires, Argentina \\ 2 Desmet Ballestra, Zaventem, Belgium
}

Received 11 February 2020 - Accepted 7 September 2020

\begin{abstract}
A minimal residual oil content in the meal coming out of the hexane extractor is a clear benefit for a crushing plant; the more oil yield the better revenue for the crusher. In a modern and efficient extraction plant, a residual oil content $\leq 0.5 \%$ for soybean meal is expected. The first step for an efficient solvent extraction is a good preparation process; its optimization makes it possible to shape the seeds for effective leaching and washing of the oil. Preparation also goes through an optimized dehulling (warm or hot dehulling) allowing, in an economical way, to maximize the protein content. The seed flaking can optionally be complemented by expanding which permits rupture of a more efficient portion of the cell walls. Solvent extraction consists in washing the prepared material in a countercurrent multistage process to enable a reasonable quantity of solvent to extract a maximal amount of oil. Major progresses in solvent extraction relate to plant production capacity increases which propelled technological improvements. Following extraction, the solvent is distilled from the miscella and recovered. A mineral oil system absorbs the residual solvent out of the effluent air stream. A single integrated unit also called desolventizer/toaster/dryer/cooler removes the solvent, toasts the meal in order to control the anti-nutritional factors and reduces moisture and temperature to levels appropriate for storage and transport. Although today the industry is mostly based on the solvent extraction process, certain strict constraints in the environmental aspects suggest alternative processes to minimize hexane emissions and even the return to mechanical operations (for example full press) allowing to completely eliminate the use of solvent at the expense of lower efficiency.
\end{abstract}

Keywords: Seed preparation / dehulling / solvent extraction / desolventization / efficiency

Résumé - Aperçu du procédé industriel de trituration de la graine de soja. Atteindre une teneur en huile résiduelle minimale est un avantage évident pour une usine de trituration, car plus le rendement en huile est élevé, plus la valeur ajoutée augmente. La performance attendue d'une usine d'extraction moderne et efficace est une teneur en huile résiduelle du tourteau $\leq 0,5 \%$. La préparation de la graine est une étape indispensable à l'efficacité de l'extraction; son optimisation permet de façonner la graine pour faciliter le déplacement de l'huile vers le solvant. Cette préparation passe par un décorticage performant (à froid ou à chaud) permettant de manière économique de maximiser la teneur en protéines. Le laminage (aplatissage) des graines est parfois remplacé par l'expansion (passage en expander) qui permet une rupture plus efficace des parois cellulaires. La matière préparée est extraite par le solvant dans un dispositif à contre-courant multi-étages conçu pour extraire un maximum d'huile avec un minimum de solvant. Les progrès majeurs de cette technologie ont porté sur l'augmentation de la capacité de production des usines rendus possibles par d'indéniables progrès dans la conception et la mise en œuvre des équipements. À l'issue de l'extraction, le miscella (mélange d'huile et de solvant) est distillé pour permettre le recyclage du solvant. Un système d'absorption à l'huile minérale permet de traiter l'air usé et de capter les vapeurs de solvants pour en éviter les pertes dans l'air. Une seule unité intégrée appelée désolvanteur-toasteur-sécheur-refroidisseur élimine le

\footnotetext{
Contribution to the Topical Issue "Technological challenges in oilseed crushing and refining / Défis technologiques de la trituration et du raffinage des oléagineux".

*Correspondence: vgibon@desmetballestra.com

${ }^{a}$ Regional Product Manager Crushing at Desmet Ballestra, Buenos Aires, Argentina.

${ }^{\mathrm{b}}$ Science Manager at Desmet Ballestra, Zaventem, Belgium.
} 
solvant du tourteau, assure l'inactivation thermique des facteurs antinutritionnels et réduit la teneur en eau résiduelle et la température à des niveaux appropriés pour le stockage et le transport. Bien qu'aujourd'hui, l'industrie soit principalement basée sur le procédé d'extraction par solvant, certaines limitations liées au renforcement des contraintes environnementales suggèrent de recourir à des procédés alternatifs pour réduire les émissions d'hexane, voire à revenir à l'extraction mécanique sans solvant au prix d'une perte d'efficacité notable.

Mots clés : Préparation des graines / décorticage / extraction par solvant / désolventisation / efficacité

\section{Introduction}

Edible oil industry goes back a long way through time, but recent decades have witnessed changes mainly due to stricter environmental and economic criteria. Today, the operation needs to comply with stringent environmental rules and, at the same time, wants to improve process efficiency for both operational costs and product quality. In general, current trends come with less chemicals and solvent use, less energy consumption, reduced environmental impact, safer process, milder operating conditions and optimized nutritional properties for the refined oil. Edible oil can be extracted from several categories of plants: plants with oil concentrated in seeds (sunflower, soybean, rapeseed...), plants producing oleaginous fruits (from pulp or kernel: palm, olive, palm kernel, olive kernel...), oleaginous germs (corn...), oleaginous beans or nuts (cocoa butter, shea butter...). The extraction methods applied are closely linked to the type of oil plant, but in all cases the main purpose is to optimize the process for a maximal oil extraction yield with minimal processing costs. After extraction, the oil is generally refined and possibly modified depending on the final applications. When oil is extracted from seeds, the first step consists in seed preparation prior to solvent extraction; indeed, being well protected inside of the plant cells, oil can't be easily extracted. A succession of treatments (conditioning, cracking, dehulling, flaking...) permits to properly weaken or break the cell walls and to shape the material in order to optimise the solvent access and to maximise the oil extraction yield. Seeds containing high amount of oil (like sunflower or rapeseed) are generally first mechanically pressed to extract a portion of crude oil (prepressing); the press cake is then subjected to solvent extraction. In some cases (rapeseed), the full pressing is an option. Despite of the environmental commitment and the health concerns, hexane is today still preferred for efficiency reasons; alternative solvents are reported in the literature, but most have not reached industrial implementation (Jeevan Kumar et al., 2017). Interest in aqueous enzymatic process has been also revived (Mat Yusoff et al., 2015); however, it is still far to be economical, the main drawback, beside the enzyme cost, being a relatively low oil yield due to emulsification issues that can hardly be avoided and the cost of the water removing. Major progress in solvent extraction relates to plant production capacity improvement; in the last 20 years, a production limit (nominal capacity) grew from about 2000 MTPD to 22000 MTPD in a single preparation and solvent extraction plant (Fig. 1). This change in production volume meant that the greatest efforts in the plant designs were focused on operational safety and yields, emphasizing quality and environmental standards. This can clearly be seen in the residual oil content and solvent and energy consumptions which sensibly improved. This also made mandatory better automation and control in the plants that substantially changed their way of operation and allowed new (huge) plants possible to operate. A point of unquestionable importance is the mechanical reliability that must be achieved in the solvent extraction plants, especially when increased installed capacity. Indeed, everything becomes "big": conveyors of the input material, extractors, desolventizers, shell and tube equipment etc. For example, there are currently conveyors whose size is the width of the extractors few years ago. On the other side, the important global awareness regarding the need to minimize environmental impact somehow enhanced efforts to optimize quality and performances of the extraction plants. In America, specially the United States, Brazil and Argentina, the outstanding raw material is soybean; the increase in the area planted together with the significant improvements in crop yields were the incontestable engine for the industry to turn to current production capacities. All this, far from being a negative scenario in the technical, brings an important opportunity, which in fact is being used in recent developments, to go to new technologies necessarily passing through optimizations of the existing setups.

This article will focus on the soybean crushing process. Of course, most of the information presented here can be adapted or extended to other seeds like for example sunflower or rapeseed.

\section{Key parameters in crushing}

The raw material in a crushing plant is the seed; main and byproducts are the meal, the crude oil, the hulls, foreign material and impurities, respectively. The crude oil is usually water degummed in the crushing plant which generates an additional flow, consisting of gums (or lecithin). Table 1 presents the main quality parameters (optimal contents) of the major products from soybean crushing. A minimal residual oil content in the meal coming out of the hexane extractor $\leq 0.5 \%$ is a clear benefit for a crushing plant. Although some plants still operate with higher values, majority challenge to get these lower values.

Utilities like steam consumption and electricity should not exceed $250 \mathrm{~kg} / \mathrm{t}$ and $25 \mathrm{kwh} / \mathrm{t}$, respectively; hexane consumption in the extraction plant is typically $0.46 \mathrm{~kg} / \mathrm{t}$. Other parameters to be considered are related to maintenance costs and operational reliability. In general, the economics make a critical difference regarding crushing business; this also means that when a plant is designed, it must properly support all the above listed parameters. At various levels, non-compliance with these parameters leads to low competitiveness.

\section{Description of the crushing process}

The complete chain from the seed to the finished products (meal and crude oil) consists in three stages: the seed preparation, the solvent extraction and the meal treatment. 


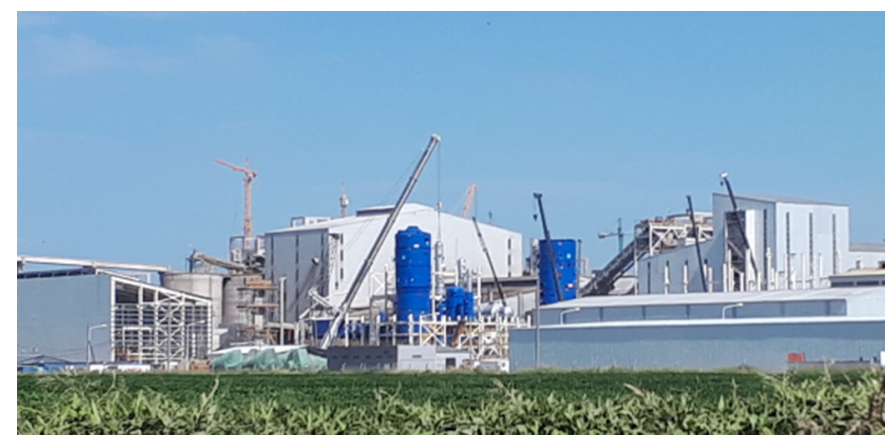

Fig. 1. The largest soybean crushing plant in the world with a capacity of 33000 MTPD (22 000 MTPD in a single plant and 11000 MTPD in a parallel line).

The seed preparation stage can be defined as a succession of operations allowing to properly shape the seed for an optimal performance of the extraction process and to ensure highly valuable final products. In this regard, it generally includes a dehulling section allowing to increase the protein content and, at same time, to reduce the final fiber content in the meal. The solvent extraction, as the name describes, consists in extraction of oil from the seeds (or press cakes) using solvent. Indeed, the solvent extraction step may or may not be preceded by pressing. Hexane has maintained the dominant position as a solvent for the major plants which extract oil from seeds; the existing technology has sufficient virtues to maintain credibility while it continues to be developed in a competitive market. There is also the advantage of well-understood industry expectations for performance, the availability of trained personnel, and established standards for safe use. It should be noted that other solvents may be required to produce different and specific products; for example, an alcohol-water mixture is used in an additional extraction step (after hexane extraction) to produce soy protein concentrate (or "SPC") by removing the sugars from standard soybean meal (Wang et al., 2004). The meal treatment is known like the necessary process to treat the meal before the final dispatch. This process is usually located in the same building as seed preparation and is thus considered many times like part of the seed preparation process. Also, the meal treatment has in common with the seed preparation the fact that in both cases all process is related to treat solid material exclusively.

\section{Block diagrams}

For the best understanding, block diagrams of each stages are presented below: preparation plant and solvent extraction plant. As mentioned above, the preparation plant includes the meal treatment section. In the preparation plant (Fig. 2), the seeds are successfully cleaned, weighted, conditioned, cracked, dehulled and flaked. Hulls purification is the process of reclaiming the small particles of soybean meats and fines from the soybean hulls removed during conditioning and cracking/dehulling. This process is economically important since the soybean meats and fines contain both soybean oil and soybean meal, each having a considerably higher value than the soybean hulls. The effectiveness of hulls purification is typically measured by the fat content of the hulls stream.
Table 1. Targeted optimal quality parameters for the meal, the hulls, the solvent extracted crude oil, the water degummed oil and the gums in soybean crushing.

\begin{tabular}{lll}
\hline Meal & Residual oil & $\leq 0.5 \%$ \\
& Protein & $\geq 46 \%$ or $\geq 47 \%^{*}$ \\
& Fiber & $\leq 3.5 \%$ \\
& Moisture & $\leq 12.5 \% * *$ \\
& Residual hexane & $\leq 200 \mathrm{ppm}$ \\
Hulls & Residual oil & $\leq 1.1 \%$ \\
& Residual hexane & $\leq 20 \mathrm{ppm}$ \\
Crude oil & Moisture & $\leq 0.1 \%$ \\
Crude degummed oil & Phospholipid & $\leq 200 \mathrm{ppm}$ \\
Gums (or lecithin) & Neutral oil & $\leq 30 \%$ \\
\hline
\end{tabular}

*: depending on countries or seed quality; **: depending on the meal protein content.

Soybean hulls have a very low bulk density; they are fibrous and are not free flowing. The purpose of hulls grinding is to increase their bulk density and flow ability, in order to prepare them for pelletizing. Hulls pelletizing is a process that uses elevated temperature, elevated moisture and high pressure to bind ground hulls into a pellet shape that is lower in dust to ease handling, and higher in bulk density to reduce storage and shipping volume. Soybean meal from the solvent extraction plant is a mix of particle sizes; it is therefore necessary to undergo several additional process steps (meal sizing) to produce a finished product that meets trading rule size specifications.

The flakes that have been shaped in the preparation plant enter the solvent extraction plant (Fig. 3). After oil extraction, the miscella is sent to the distillation unit: the crude oil is recovered, and the hexane is recycled back. A mineral oil system allows to purify the air leaving the solvent recovery section. The meal is conveyed in the desolventiser whose purpose is to remove the solvent, toast the meal to control antinutritional factors, and reduce the moisture and temperature to appropriate levels. Then the meal is lead to the meal treatment plant for sizing.

In these Figures 2 and 3, the thick solid lines correspond to the main flow and to marginal streams (fines, light pieces, ...); the thinner solid lines represent the liquid connections (process water, steam condensate (c), cooling water, oil, miscella) and the dotted lines concern vapor (s) and air connections.

\section{Preparation process}

The protein and fiber content in meal and the residual oil content in hulls must comply with the quality objectives targeted in the preparation and meal treatment plant. Properly removing the hulls allows increasing the meal protein content, but also reduces the meal fiber content. A basic mass balance applied to soybean recognizes three main parts on the seed stream: the meat (92-93\%), the hulls (6-7\%) and the foreign material (balance). Utilities like steam consumption and electricity are typically $\leq 90 \mathrm{~kg} / \mathrm{t}$ and $\leq 20 \mathrm{kwh} / \mathrm{t}$, respectively. Minimizing the fiber in favor of the protein content in the meal is then a must, and this goes, without doubts, through an efficient dehulling process. For this reason, there is a whole section dedicated to dehull the seeds. The standard target in dehulling is to keep the remaining hull content under $1 \%$ (that is to remove about $85 \%$ of the inlet hulls). 

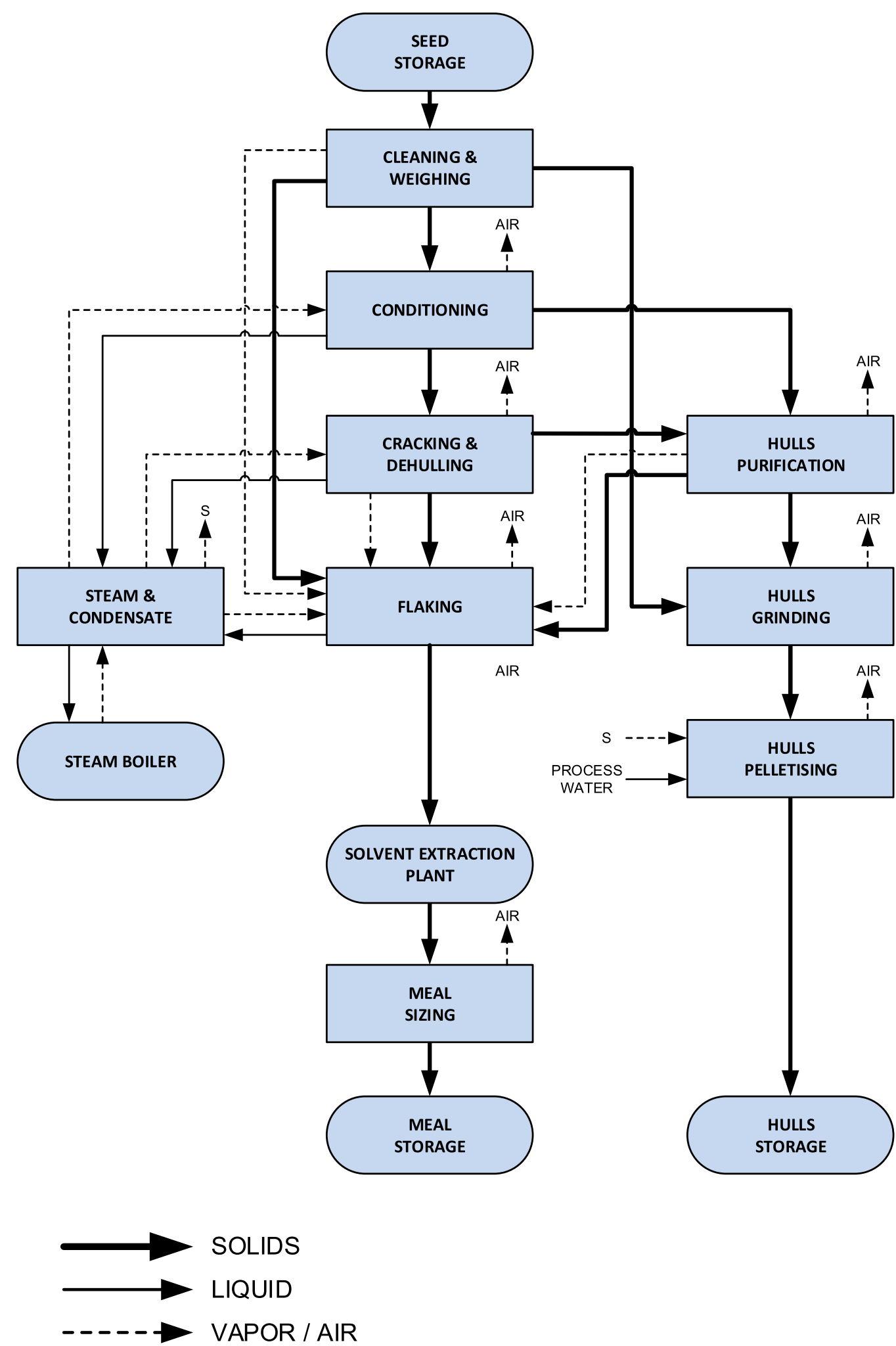

Fig. 2. Seed preparation and meal treatment block diagram applied to dehulled soybean (Desmet Ballestra Courtesy).

\subsection{Dehulling technology}

In the oilseed industry applied to soybean, there are three different types of dehulling: the cold dehulling, the warm dehulling and the hot dehulling. The terms cold, warm and hot refer to the temperature of the seeds during dehulling. It can be mentioned that the worse the quality of the seed, the higher the optimal dehulling temperature; high temperature is required to get reasonable level of dehulling and thus optimal protein content in the meal. Cold dehulling used to be the most 

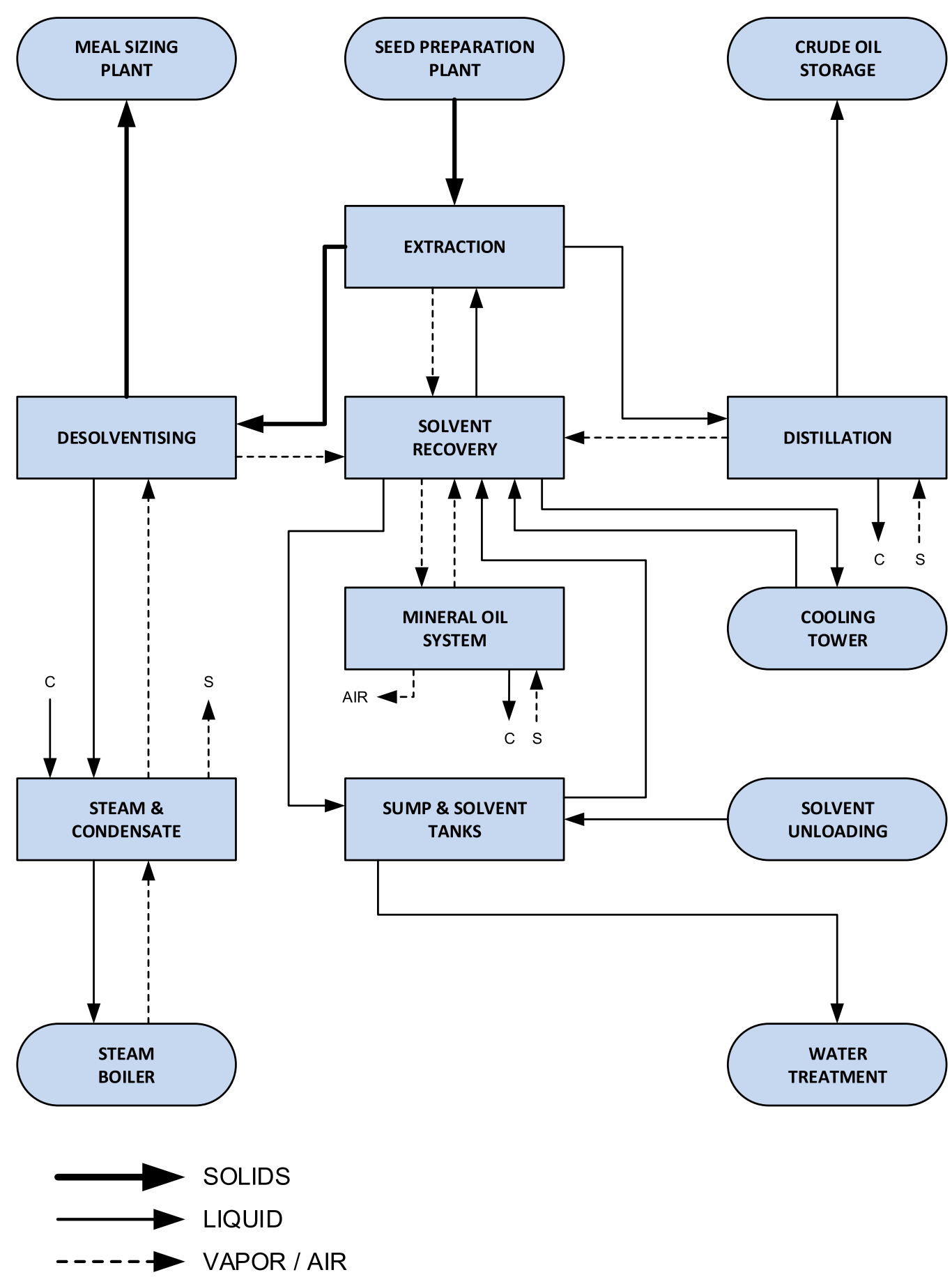

Fig. 3. Solvent extraction block diagram applied to soybean (Desmet Ballestra Courtesy).

common type and is suitable for all types of soybeans. But soybeans need to be heated twice; that is an expensive system with setup cost and expenditures relatively higher compared to the other methods. The warm dehulling (Fig. 4) is the most affordable system with a lower setup cost and a single heating step. Warm dehulling is an effective means of thorough hull removal in the seed preparation process which enables producing a high protein, low fiber meal after solvent extraction. Warm dehulling is especially applicable when processing high protein soybeans, and when soybeans have aged more than 3 months or are high moisture which enables the hull to separate from the meats after conditioning. In warm dehulling, the conditioned soybeans fall by gravity through two series of roller mills and aspirators for sequential size reduction and hull separation. Hot dehulling is especially important when processing low protein soybeans, and when soybeans have aged less than 3 months or are low moisture which causes the hull to remain adhered to the meats after conditioning. In hot dehulling, the conditioned soybeans are first subjected to a thermal shock treatment that breaks the 


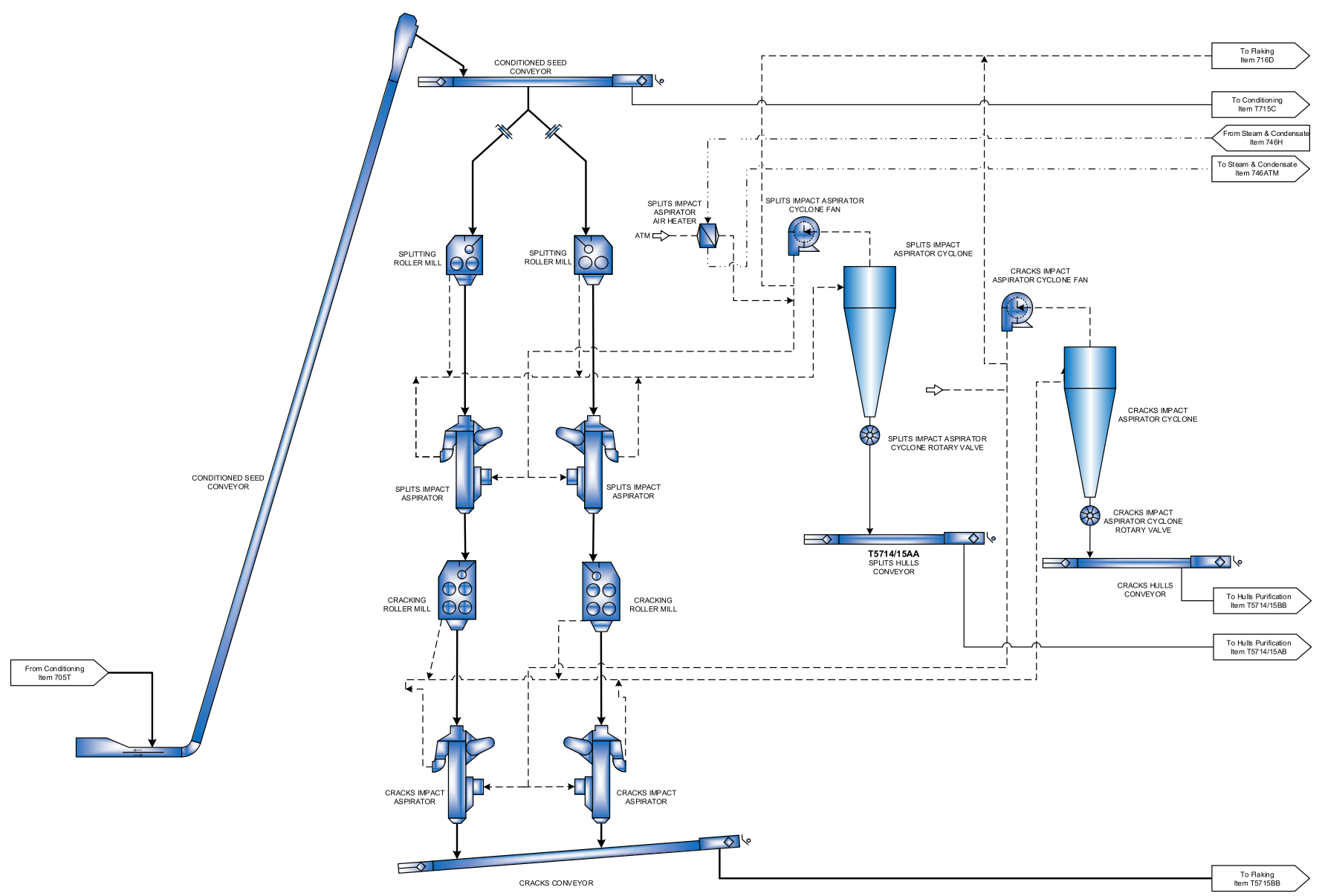

Fig. 4. Warm dehulling flowsheet (Desmet Ballestra Courtesy).

bond between the hull and the meats (Fig. 5). Typically, the hot dehulling is more costly (OPEX wise) as it requires more steam and electrical power; for this reason, it is mainly reserved when seed quality demands such technology. This kind of dehulling is only mandatory when the seeds are not stabilized, when the bean is too fresh or, eventually, at the beginning of the crop. The dehulling installation should be flexible in order to use the hot dehulling only when it is necessary.

\subsection{Oil content in the hulls}

The oil content in the removed hulls is another important point to consider. The natural oil content in hulls is quite low; it is typically between 0.5 to $0.8 \%$ (botanical fatty matter content), depending on the seed origin. Ideally, the closer to the botanical content is the oil content in the hull stream, the better. More oil in the hull stream corresponds to too high meal entrainment with large amount of oil content. Oil loss in this stream is the biggest economical loss per $\mathrm{kg}$, the most expensive material (the oil) being drawn in the cheapest byproduct (the hulls). On the other side, part of meal stream is also lost. The next solutions tend to avoid it. First is to minimize fines and powder, in such a way to make harder the entrainment of meal particles with the aspirated hulls; this brings the aspects of having a good maintenance on the cracker rolls with good edge on the grooves and avoid too small cracks granulometry. The second is to make a good separation (screening) of the hulls and small pieces of carry over meat (hull purification section); it is very important to have enough screening area to make a proper separation of hulls and meat pieces.

\subsection{Flaking technology}

Another important process that is of critical importance in the preparation plant is the flaking section. A good flaking is essential for the best solvent extraction efficiency. The main goal of flaking is to expose as much as possible the oil to the solvent (or miscella) in the solvent extractor. Flaking is the process wherein the warm, pliable cracked and dehulled soybean shape, approximately $3 \mathrm{~mm}$ across, is mechanically squeezed into a flake shape, $0.3-0.4 \mathrm{~mm}$ in thickness and 10 $15 \mathrm{~mm}$ in diameter. The cellular structure of the cracked soybean is severely distorted during flaking which tears open many of the cell walls, enabling the oil to be extracted more readily during the solvent extraction process. In addition, the thickness reduction minimizes the number of cell walls that the solvent needs to diffuse through to extract the oil from the center of the flake. The seed can be visualized as being an 


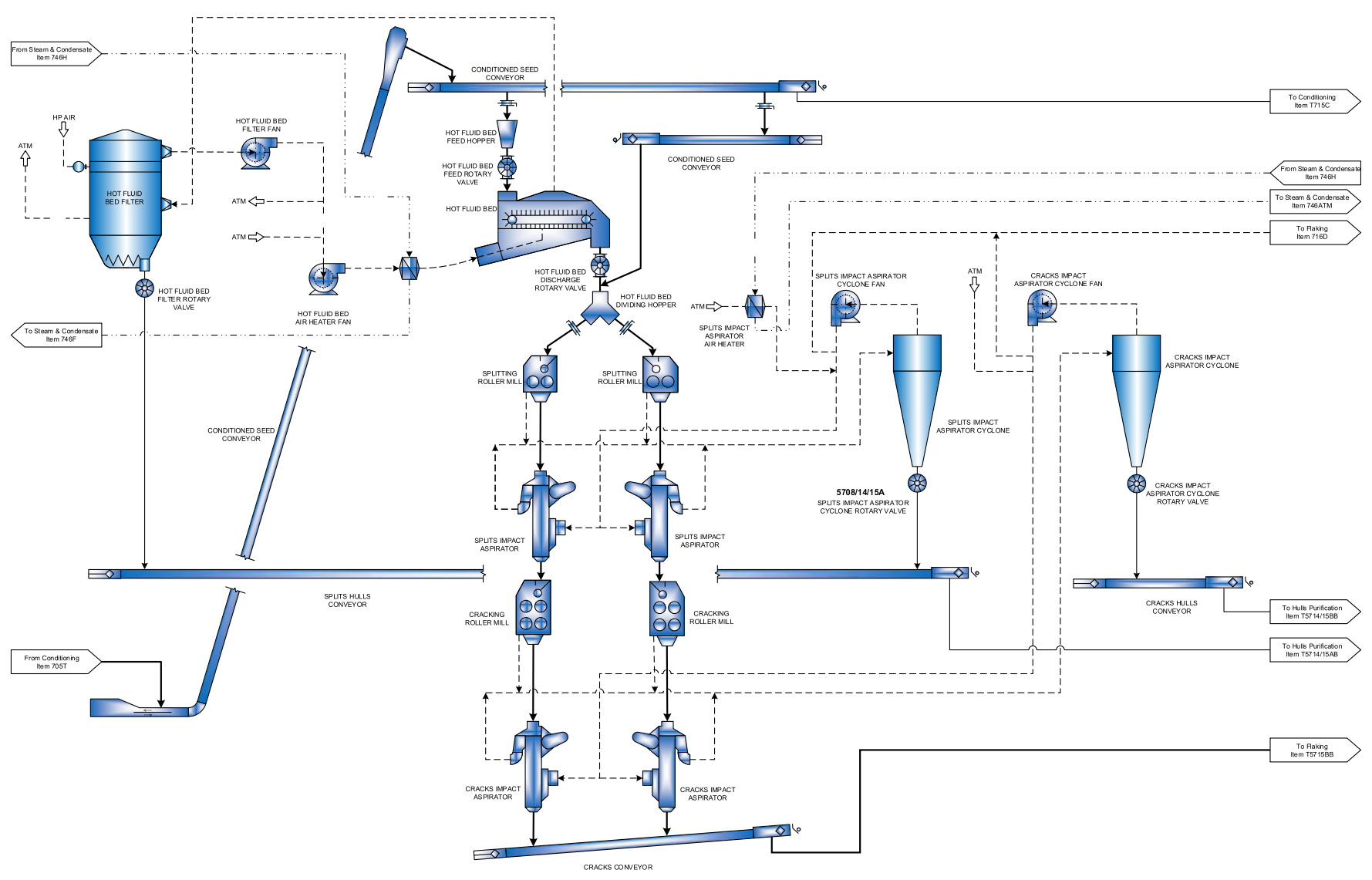

Fig. 5. Hot dehulling flowsheet (Desmet Ballestra Courtesy).

accumulation of cells of about $0.02 \mathrm{~mm}$ each; each cell is surrounded by cell wall which is basically fiber; inside are the protein bodies and the oil bodies. This can be seen in a soybean cell microscopic structure (Cambell and Glatz, 2009) (Fig. 6); the oil bodies as such are not easily accessible by the solvent (or miscella).

Flaking machines (or flakers) (Fig. 7) are designed to turn the broken/dehulled oilseeds into thin flakes for the subsequent oil extraction (Fig. 8a). They have the task to break as much as possible the cell walls which are the harder part of the cell to be passed through for the solvent (or miscella); a tearing force is given in the flakes, so that the cracks (halves to eighths of the seed) turn into flakes.

One critical aspect in the flaking process is the aspiration by the flakers: indeed, during this, some water evaporation occurs which can bring superficial moisture on the flakes and further reduces in a sensible way the pass of hexane through the material (the percolation rate) in the solvent extraction plant. In good operation, this must be minimized since it can drastically impact the oil extraction performance. Typical flake thickness for a good extractor sizing is about $0.38-0.40 \mathrm{~mm}$. Other important aspect in the seed preparation section is known as the milling defect; conceptual wise that is the minimum residual oil content potentially achievable in an ideal or perfect extractor. The main process in the preparation plant to get a good milling defect is the flaking; this explains why the flaking is one of the most critical steps. Reasonable milling defect for soya should be less than $0.2 \%$.
As a complement to flaking, expanding enables more efficient rupture of the cell walls; ruptured walls are subjected to quicker solvent extraction, by leaching and washing. During expanding, the injected steam heats the product by condensing (high temperature and short time); the pressure release at the outlet explodes the cells, making oil easier available and creating a porous but strong structure of proteins. Oil bodies of the ruptured cell structure are more exposed, which favors solvent penetration and improve oil dissolution in the expandates (Fig. 8b).

\section{Solvent extraction process}

The residual oil content in meal, the residual hexane content in meal and in oil and the oil and meal moisture are the main quality parameters targeted after solvent extraction and meal treatment. In the solvent extraction section, utilities like steam consumption and electricity are typically $\leq 150 \mathrm{~kg} / \mathrm{t}$ and $\leq 5 \mathrm{kwh} / \mathrm{t}$, respectively, with hexane consumption of $0.46 \mathrm{~kg} / \mathrm{t}$. This process can be divided in four sections: the extraction, the desolventizing, the distillation/solvent recovery and the mineral oil system.

\subsection{Extraction}

The purpose of this section is to wash the prepared material with commercial hexane, in a countercurrent multistage 


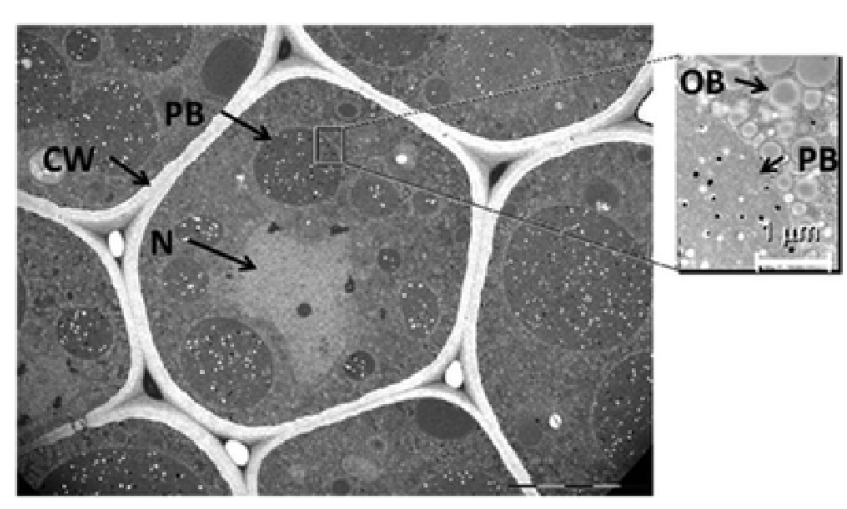

Fig. 6. TEM (Transmission Electronic Microscopy) of soybean cotyledon cell cross-section. PB: protein body; CW: cell wall; N: cell nucleus; OB: oil body (Cambell and Glatz, 2009).

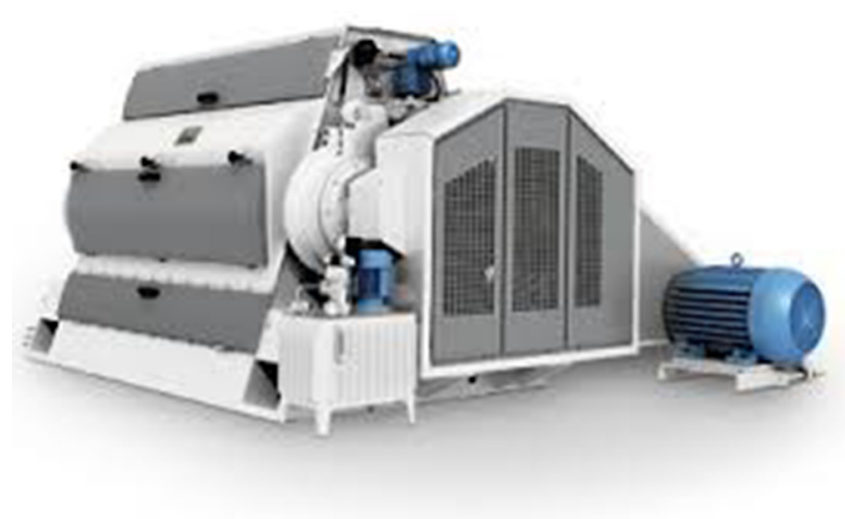

Fig. 7. Typical flaker used in soybean crushing (Desmet Ballestra Group-Web site).

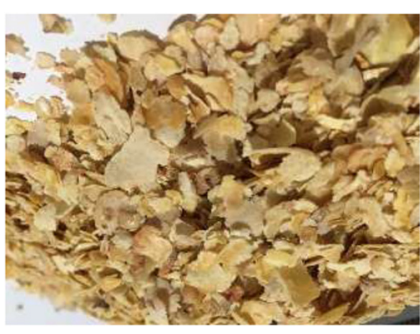

(a)

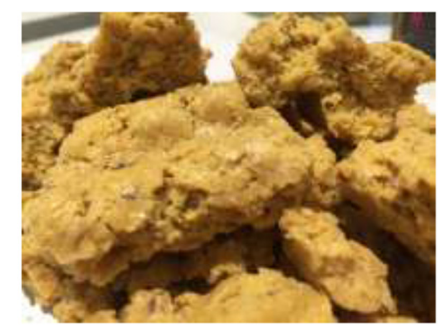

(b)
Fig. 8. (a) Soybean flakes; (b) Soybean expandates (Desmet Ballestra Courtesy).

process in order to enable a reasonable quantity of solvent to extract a maximal amount of oil; actually, it is not a pure $n$-hexane but a mix of isomers with very similar properties. After washing, the solvent-laden meal drains by gravity and then discharges to the meal desolventizing section; meanwhile, the oil/solvent mixture, commonly called miscella, discharges to the distillation section. Although there are many mechanical different extractor designs spread all over the world, the main parameters that rule the good efficiency of a solvent extractor

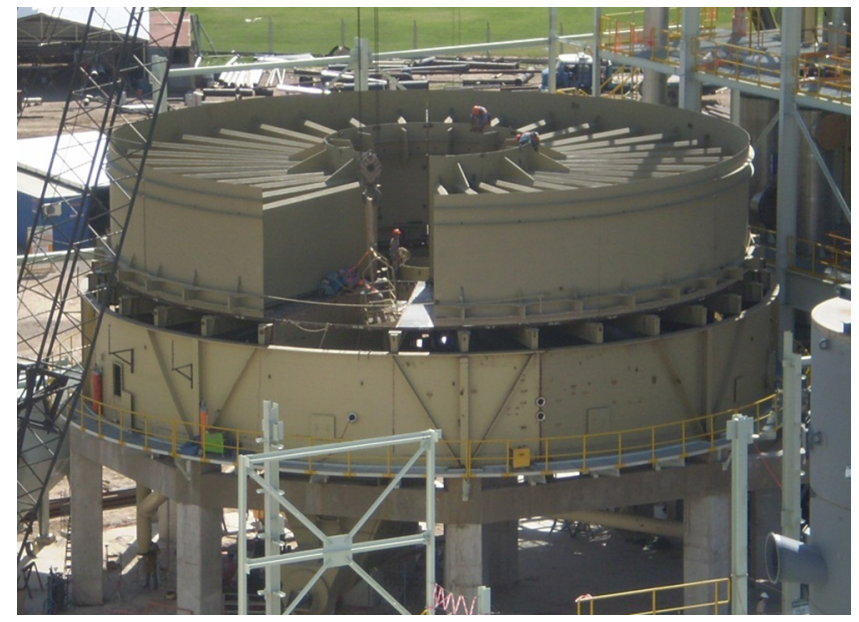

Fig. 9. A large solvent Reflex ${ }^{\circledR}$ extractor (immersion/deep bed) in assembly phase (Desmet Ballestra Courtesy).

are all identical and listed hereafter. First is the contact time between the prepared material and the solvent (or miscella); this parameter is of critical importance for a good yield. Second is the extraction temperature: the higher the temperature, the lower the oil viscosity and the higher the hexane diffusion inside the flakes. The extraction performance can be improved by increasing the temperature of the material and of the solvent. The ideal temperature for the material incoming from the preparation section is $\sim 65^{\circ} \mathrm{C}$; however, the solvent recommendable temperature is $\sim 61{ }^{\circ} \mathrm{C}\left(\sim 2^{\circ} \mathrm{C}\right.$ below the 1 st drop solvent distillation). Third is the flake thickness and cracks: these are important parameters (optimal flake thickness, minimal milling defect and no cracks) in relation to the solvent extraction efficiency. It is critical to avoid the presence of cracks in order to get reasonable residual oil content in the meal. In a modern and efficient extraction plant (Fig. 9), a residual oil content $\leq 0.5 \%$ for soybean meal is expected. A number lower than this value is even quite common in good-sized extraction plants and makes the difference in a competitive market.

\subsection{Desolventizing}

The solvent-laden meal exiting the extractor contains 26$30 \%$ solvent by weight. The purpose of the desolventizing process is to remove the solvent from the solvent-laden meal, to toast the meal in order to control the anti-nutritional factors, and to reduce moisture and temperature to levels appropriate for storage and transport; this operation is usually performed thanks to a single integrated unit often called desolventizer/ toaster/dryer/cooler (DTDC) (Fig. 10). Raw beans, like soybean, cannot be used as such for animal feed or human food, since they contain several antinutritional factors: trypsin and chymotrypsin inhibitors, lectins, urease, allergenic factors, lipases and lipoxygenases, affecting the digestion in the stomach (Becker-Ritt et al., 2004). The toasting aims to deactivate, modify or reduce these contents through proper heat treatment in order to minimize or eliminate their adverse effect; however, caution must be taken to assure that no destruction of the oilseed protein occurs during this operation. 


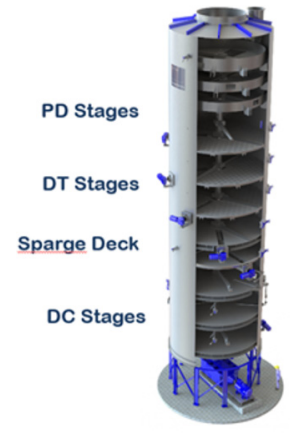

(a)

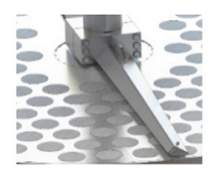

(b)

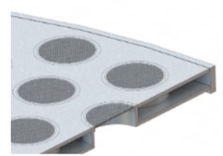

(c)
Fig. 10. Schematic view of a DTDC (Dimax ${ }^{\circledR}$ ) with some mechanical details (a) Complete DTDC sketch with stages: PD: Pre-Desolentizing stages; DT: Desolventizing/Toasting stages; DC: Drying/Cooling stage; (b) Counter-current tray with stirrer; (c) Double bottom mechanical detail (Desmet Ballestra Courtesy).

Majority of the heat supplied for evaporating the solvent from the meal is coming from the latent heat of condensing live steam, which simultaneously increases the meal moisture to facilitate toasting. The drying and cooling of the meal are accomplished by passing air through a fluidized bed of meal. The solvent and water vapors exiting the desolventizing process pass through a scrubber to remove potential meal particles existing in that stream before entering to distillation for heat recovery. The most critical aspects of the meal desolventizing process are the residence time and the steam distribution. The residence time refers to the contact time between the meal and direct live steam at a temperature above $100{ }^{\circ} \mathrm{C}$; this allows complete desolventizing $(25 / 30 \mathrm{~min}$.) and good inhibition of the antinutritional factors: trypsin inhibitors in the case of soybean $(\sim 20 \mathrm{~min}$.). The contact between direct steam and the solid material (steam distribution) is critical during all the desolventizing process. There are different equipment designs allowing such good contact, but the minimum pressure drop through the different stages is the best way to reach the goal. The use of rotary valves helps in a good steam distribution, to ensure the best contact between steam and the solid material. Total hexane losses are mainly observed in the DTDC ( $90 \%$ of the total quantity lost). In addition, the steam consumption in the DTDC exceeds $70 \%$ of the total consumption of the crushing plant (significant energy to evaporate the hexane at the outlet of the extractor). From an economical point of view, the meal stream is therefore the largest turn-over of the crushing plant; this makes DTDC a crucial equipment, explaining the need of paying close attention to the OPEX when time is to decide a new investment (Fig. 11).

\subsection{Distillation and solvent recovery}

The oil/solvent mixture (miscella) leaving the extractor contains $70-80 \%$ of solvent by weight. The purpose of distillation is to thermally separate the miscella into a liquid oil and solvent vapor fraction. The energy efficiency of the distillation is maximized through optimum use of the available heat at the discharge vapor stream of the DTDC, of the available heat from the condensate flash tank, and of heat recovery within distillation itself. Although distillation does

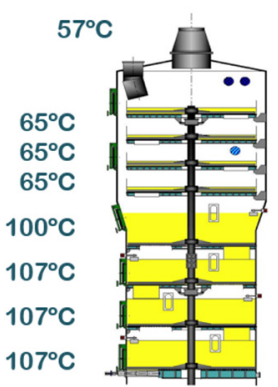

(a)

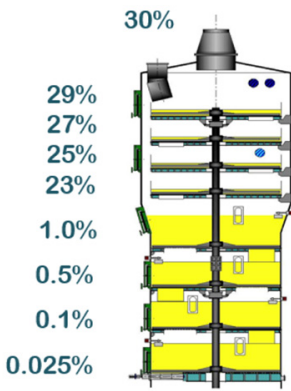

(b)

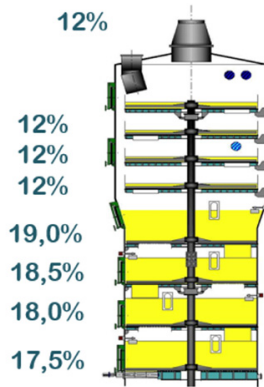

(c)
Fig. 11. Main DTDC operational sequences: (a) Meal temperature profile $\left({ }^{\circ} \mathrm{C}\right)$; (b) Meal hexane content profile (\%); (c) Meal moisture profile (\%) (Desmet Ballestra Courtesy)

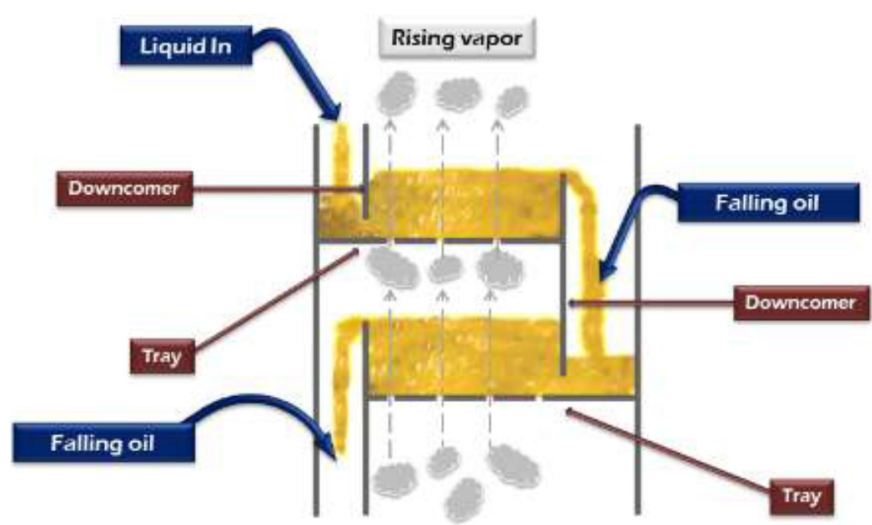

Fig. 12. A modern and high-performance oil stripper design scheme (Desmet Ballestra Courtesy).

not have a big influence on OPEX side (due to the amount of energy savings made in modern plants), it is an important section because the product leaving this section (the oil) is also the most expensive. It is therefore essential to have an optimal recovery using very reliable equipment, always in good working order. One important aspect is to minimize the residual hexane in the extracted oil. Today, well-designed stripper equipment (Fig. 12) will ensure less than $20 \mathrm{ppm}$ of hexane in the extracted oil. Moreover, it is important not to damage the crude oil or to make its further refining perilous; with the current technology, it is possible to distill the miscella at temperatures under $100{ }^{\circ} \mathrm{C}$ while allowing low residual hexane content in the oil.

\subsection{Mineral oil system}

The effluent air leaving solvent recovery contains an equilibrium concentration of solvent in the range of $50-70 \%$ by weight, dependent upon vapor temperature. The purpose of the mineral oil system is to absorb the residual solvent out of this effluent air stream to less than $1 \%$ by weight of solvent before it is safely discharged to atmosphere. The solvent absorption takes place into cool mineral oil. After absorbing the solvent, the cool mineral oil is heated and then the solvent is steam stripped out of the mineral oil under vacuum. The hot, 
stripped mineral oil is then cooled and circulated back for absorption, forming a closed loop mineral oil system.

\section{Water degumming}

The crude oil from the solvent extraction process contains water soluble components, primarily comprised of phospholipids, which need to be removed from the oil to enable minimum precipitation and settling during oil transport and long-term storage. It is generally convenient not to exceed $0.1 \%$ moisture content in the crude oil in order to minimize gums (lecithin) settlement. Usually in operation in the crushing plant, the water degumming process involves adding water to the crude oil, hydrating the water-soluble components, and then removing the majority via centrifugal separation. The light phase after centrifugal separation is the crude degummed oil, and the heavy phase is a combination of water, water soluble components and entrained oil, collectively referred to as gums (lecithin). The crude degummed oil is dried and cooled before being sent to storage: the lecithin is usually pumped back onto the meal for animal feed or turned into foodgrade. OPEX wise, it must be mentioned that water degumming is a potential big neutral oil loss for a cheap stream. Good figures of neutral oil in gums are in the range of $30 \%$; in order not to exceed this number, it is expected to keep the machines involved in this section (centrifuges) with a good level of maintenance. To counter these oil losses, enzymatic processes such as enzymatic water degumming or enzymatic gums de-oiling can be implemented.

\section{Alternative processes}

Although today the industry worldwide is based on the solvent extraction process as described here, certain strict constraints in the environmental aspects start to suggest alternative processes. Some European governments impose a very low hexane emission rate on the oilseed industry. Nowadays, technology is far enough and capable of reaching the requested figures. However, certain alternatives to minimize hexane emissions tend to appear like the Regenerative Thermal Oxidation (RTO) process (Choi and Yi, 2000). A regenerative thermal oxidant is a type of air pollution control equipment designed to break down volatile organic compounds (VOCs), hazardous air pollutants (PAHs) and other solvents suspended, in $\mathrm{CO}_{2}$ and harmless water vapor by heating the exhaust air to a very high temperature. However, the industry is still hesitant to use this type of technology. That brings the option to go back to the initial technology of the oilseed industry (really improved today) of mechanical press. That option would imply a significant backward in terms of process performance (high oil content in meal) but on the other hand would give the chance of having almost negligible impact environment wise. At the same time, in green field projects, the CAPEX would tend to be reduced. Also, it would much easier to distribute the plants all over as the process wouldn't be necessarily continuous $(24 \times 7)$. Although it is not used for soybean, the mechanical press process is applied today for seeds with high oil content like sunflower, rapeseed etc., in general for pre-pressed purpose; the intermediate residual oil content in press cake is about $20 \%$. This is sent to the solvent extraction plant to further reduce the oil content in meal to less
Table 2. Evolution of Residual hexane contents in oil, meal and air.

\begin{tabular}{lll}
\hline & In the nineteens & 2020 \\
\hline Residual hexane in oil & $400-500 \mathrm{ppm}$ & $<20 \mathrm{ppm}$ \\
Residual hexane in meal & $300-400 \mathrm{ppm}$ & $<250 \mathrm{ppm}$ \\
Residual hexane in air & $50 / 70 \mathrm{gr} / \mathrm{m}^{3}$ & $<10-7 \mathrm{gr} / \mathrm{m}^{3}$ \\
(out of mineral oil system) & & \\
\hline
\end{tabular}

than $1 \%$. Besides, full pressing can be applied in stand-alone configurations (when no solvent extraction plant is available); full pressing only allows a residual oil of $\sim 6 \%$ in the meal. Although this route is less economical in relation to its reduced extraction efficiency, the issue of solvent emission restrictions tends to position the mechanical extraction as an alternative process which should be seriously considered in the oilseed industry.

\section{Technological evolutions}

As mentioned above, there has been a significant increase in the capacity of oil extraction facilities in the past 40 years, which mostly impacted the technology development, not always disruptive but mainly incremental improvements in different fields. One typical example is the dehulling, which evolved from the cold dehulling to the warm and hot dehulling. On top of the better quality of final product for some seed qualities, it brought savings of about 20 to $25 \mathrm{~kg}$ steam $/ \mathrm{t}$ of seed. As lateral benefit, the residual oil in hulls is also improved, bringing down the oil in hull from almost $2 \%$ to $1 \%$ (for soybean). In addition, the evolution of technologies in solvent extraction have made it possible to dramatically reduce hexane residual contents in the oil, in the meal and in the air (Tab. 2).

Next to that, the so-called "fugitive" losses (hexane losses through mechanical seals, equipment man doors...) are today highly reduced, in such way that all together the total hexane consumption can be reduced from of 1.5-2 to 0.6 liters/t of seed. Another aspect that must be mentioned it is the energy consumption reduction thanks to optimal heat recovery. Technological re-designs have allowed to take profit of unused or residual heat at the benefit of other lower temperature streams. As a result, a steam consumption of about $330 \mathrm{~kg} / \mathrm{t}$ of seeds for an entire preparation and solvent extraction plant can, in the best case, be reduced to $220 \mathrm{~kg} / \mathrm{t}$ or even less.

\section{Conclusion}

The complete chain from the seed to the finished product consists in three stages: the seed preparation, the solvent extraction and the meal treatment. As far as solvent extraction is concerned, the advances made in recent decades have been mainly based on production capacity increase in plants. This change in production volume means that the greatest design efforts are focused on maximum yields and operational safety, with an emphasis on quality and environmental standards. This can be clearly seen in residual oil content in meal and in solvent and energy consumption that have improved historically. Hexane has maintained the dominant position for the major plants which extract oil from seeds. The protein and fiber content in meal and the residual oil content in hulls are the 
quality objective targeted in the preparation and meal treatment plant. Minimal residual oil content in the meal and low residual hexane content in the meal and in the oil are the main quality parameters aimed after solvent extraction. An extensive evolution in extraction techniques and equipment design, an evolution toward every greater economic efficiency, safety and ease of operation are the main features of the latest developments.

\section{References}

Becker-Ritt AB, Mulinari F, Vasconcelos IM, Carlini CR. 2004. Antinutritional and/or toxic factors in soybean se eds comparison of different cultivars adapted to the southern region of Brazil. J Sci Food Agric 84(3): 263-270.
Cambell KA, Glatz CE. 2009. Mechanisms of aqueous extraction of soybean oil. J Agric Food Chem 57(22): 10904-10912.

Choi BS, Yi J. 2000. Simulation and optimization on the regenerative thermal oxidation of volatile organic compounds. Chem Eng $J 76$ (2): 103-114.

Jeevan Kumar SP, Rajendra Prasad S, Banerjee R, Agarwal DK, Kulkarni KS, Ramesh KV. 2017. Green solvents and technologies for oil extraction from oilseeds. Chem Cent $J 11$ (9): 1-7.

Mat Yusoff M, Gordon M, Niranjan K. 2015. Aqueous enzyme assisted oil extraction from oilseeds and emulsion deemulsifying methods: A review. Trends Food Sci Technol 41(1): 60-82.

Wang H, Wang T, Johnson LA. 2004. Preparation of soy protein concentrate and isolate from extruded-expelled soybean meal. J Am Oil Chem Soc 81(7): 713-717.

Cite this article as: Demarco A, Gibon V. 2020. Overview of the soybean process in the crushing industry. $O C L 27: 60$. 